\title{
Elisa Detection of Salivary Levels of Cd44sol as a Diagnostic Test for Laryngeal Carcinomas
}

\author{
Eugenia Allegra $^{1 *}$, Serena Trapasso ${ }^{1}$, Antonella Sacco ${ }^{2}$, Teodoro Aragona1, Antonino Belfiore ${ }^{2}$ and Aldo Garozzo ${ }^{1}$
}

${ }^{1}$ Otolaryngology-Head and Neck Surgery, Department of Medical and Surgical Sciences, University Magna Graecia of Catanzaro, Campus Universitario, Località Germaneto, Viale Europa, 88100, Catanzaro, Italy

${ }^{2}$ Endocrinology Unit, Department of Clinical and Experimental Medicine, University Magna Graecia of Catanzaro, Campus Universitario, Località Germaneto, Viale Europa, 88100 Catanzaro, Italy

\begin{abstract}
Background: The soluble fraction of the CD44 protein (CD44sol) appears to be a possible candidate screening marker for the early diagnosis of head and neck tumors. The aim of our study was to ascertain the levels of CD44sol in the saliva of patients with laryngeal carcinoma and compare them with those of a control group of individuals to assess the reliability of the test as diagnostic marker.
\end{abstract}

Methods: Ninety-two individuals with suspected laryngeal cancer who were submitted to biopsy were selected for the study. Forty adults who underwent surgery for head and neck benign disease were recruited to form a control group. The sampling of saliva was performed on the day before the laryngeal biopsy in the patient group and on the day before surgery in the control group. CD44sol levels were detected using the ELISA method.

Results: The levels of CD44sol were significantly higher in the patient group than they were in the control group $(31.4 \pm 27.3$ vs. $9 \pm 7.1 \mathrm{ng} / \mathrm{mL})$. CD 44 sol levels were not related to smoking and drinking habits. Analysis of the clinical data revealed an absence of significant differences between the study groups according to tumor site, histological grade, and clinical stage of $\mathrm{T}$ and $\mathrm{N}$. The salivary levels of CD44sol were higher in advanced-stage (stages III and IV) compared with early-stage disease (43.2 $\pm 32.2 \mathrm{vs.} 32.2 \pm 20.5 \mathrm{ng} / \mathrm{mL}$ ). Sensitivity and specificity were calculated based on the ROC curve and exhibited best accuracy using a predictive probability cut-off point of $10 \mathrm{ng} / \mathrm{mL}$, with corresponding estimates of sensitivity and specificity of $89.5 \%$ and $83.3 \%$, respectively.

Discussion: The determination of CD44sol levels in the saliva of patients with laryngeal carcinoma using ELISA seems to be a promising diagnostic test in terms of high sensitivity and specificity, low cost and noninvasiveness of the technique.

Keywords: Soluble CD44; Saliva; ELISA; Head and neck squamous cell carcinoma; Screening

\section{Background}

Head and neck squamous cell carcinomas (HNSCCs) represent about $10 \%$ and $4 \%$ of all malignancies in men and in women, respectively. In Italy, about 5,000 and 500 new cases of larynx cancer per year are reported among men and women, respectively [1].

Laryngeal cancer mainly affects people over 55 years of age and it is more common in males. The most frequent symptoms of these tumors are unexplained and persistent dysphonia (more than 2 weeks) with changes in vocal tone, pain and difficulty swallowing, persistent ear pain when swallowing, or neck adenopathy. Based on the data available, it is not possible to determine whether routine screening for laryngopharyngeal cancers, i.e., fibrolaryngoscopic examination of the oral and pharyngolaryngeal district in all smokers and drinkers older than 60 years, is as effective for individuals who do not have typical symptoms.

Recently, the idea that a simple saliva test may become an immunoassay-based screening test for the early diagnosis of tumors of the head and neck has emerged as a focus of research [2]. These studies were based on the possibility of encountering significantly higher levels of a particular antigen in the saliva of patients.

The soluble fraction of the CD44 protein (CD44sol) appears to be a possible candidate as a screening marker for the early diagnosis of head and neck tumors, because of its stem-like properties. The CD44 molecule is a type I transmembrane glycoprotein that is expressed in many cell types of mesenchymal and neuroectodermal origin. It functions mainly as an adhesion molecule and as a mediator of the cellular internalization of hyaluronic acid (HA). The interactions between HA and CD44 influence its adhesion to components of the extracellular matrix and are involved in cell aggregation, proliferation, and migration and angiogenesis. These biological properties are essential for the normal physiological activity of cells; however, in certain conditions, they are associated with pathological activity and can also be implemented in tumor cells [3]. In addition to HA, CD44 binds to fibronectins, the invariant part of the major histocompatibility complex class II (MHC-II) molecules [4], and high-molecular-weight proteoglycans [5]. The heterogeneity of these ligands is based on the fact that the gene that encodes CD44 is composed of 20 exons: the first five and last five exons are constant and the central 10 exons are subjected to alternative splicing, thus constituting the "variable region"

*Corresponding author: Prof. Eugenia Allegra, Unità Operativa d Otorinolaringoiatria, Università "Magna Graecia" di Catanzaro, Viale Europa, Località Germaneto, 88100 Catanzaro, Italy, Tel: + 0961-3647130; Fax: + 09613647131; E-mail: eualle@unicz.it

Received September 02, 2012; Accepted September 20, 2012; Published September 22, 2012

Citation: Allegra E, Trapasso S, Sacco A, Aragona T, Belfiore A, et al. (2012) Elisa Detection of Salivary Levels of Cd44sol as a Diagnostic Test for Laryngeal Carcinomas. J Cancer Sci Ther 4: 330-334. doi:10.4172/1948-5956.1000163

Copyright: @ 2012 Allegra E, et al. This is an open-access article distributed under the terms of the Creative Commons Attribution License, which permits unrestricted use, distribution, and reproduction in any medium, provided the original author and source are credited. 
of the receptor. The most common isoform of the receptor is CD44 standard (CD44st), which is highly expressed in hematopoietic cells. About 30 CD44 receptor variants (CD44v) have been identified, many of which appear to be expressed in tumor cells, that arise via alternative splicing at the extracellular proximal portion of the receptor. The extracytoplasmatic domain of $\mathrm{CD} 44$ receptors in pathological conditions/cancer is detached and it is released in biological fluids as the soluble fraction of the receptor (CD44s or CD44sol) [6].

Few studies of CD44sol in HNSCC exist in the literature; some studies considered the plasmatic levels of CD44sol, but found no significant elevation in patients compared with controls, in contrast to what was observed in tumors involving the colon and in breast cancer $[7,8]$, presumably because of the release of different CD44sol isoforms in the plasma and the greater burden of these tumors compared with HNSCC [9]. A pilot study performed by Franzmann et al. [10] in patients with head and neck carcinoma indicated that the levels of CD44sol are seven times higher in the saliva of patients compared with controls, suggesting that the CD44sol test is highly specific for HNSCC. The presence of CD44 in the saliva seems to be a promising marker of HNSCC; in addition, this test seems to be more effective in saliva compared with the peripheral blood circulation.

Recent studies have attributed an important function to CD44 as a biomarker of a cellular subpopulation, cancer stem cells (CSCs), which exhibit characteristics of self-renewal and tumor initiation, progression, invasion, metastasis, and recurrence, as well as chemoand radiotherapy resistance [11]. This cell subpopulation, which was isolated for the first time by Bonnet and Dick [12] using samples of acute myeloid leukemia, has also been identified in solid tumors [1318]. In head and neck tumors, Prince et al. [19] first identified a cellular subpopulation expressing the surface marker CD44, which exhibited stem-like characteristics and was capable of reproducing after tumor implantation in immunosuppressed mice. Considering the implication of CD44 in the activation of cell replication, its antiapoptotic activity, and its potential as a marker of CSCs in epithelial tumors, we decided to study the role of CD44st in head and neck tumors by focusing on the identification of its soluble fraction in the saliva of patients with laryngeal cancer.

The aim of our study was to ascertain the levels of CD44sol in the saliva of patients with laryngeal carcinoma who were previously untreated and compare them with those of a control group of individuals, to assess the reliability of the test as a diagnostic marker.

\section{Materials and Methods}

Ninety-two individuals received at the Department of Otorhinolaryngology of the "Magna Græcia” University of Catanzaro from 2010 to 2011 for suspected laryngeal cancer and who were submitted to biopsy were selected for the study. Forty adults who underwent surgery for head and neck benign disease were recruited to form a control group. We excluded subjects who were previously treated for carcinoma of the head and neck or other malignancies and patients with a history of systemic diseases and acute or chronic inflammation of the oral cavity and salivary glands (dental abscesses, pericoronitis, gingivitis, sialadenitis, and stones in the salivary glands), patients already receiving radio- or chemotherapy, and individuals receiving pharmacological treatment with substances that can alter salivation, quantitatively and qualitatively. For each patient, clinical and anamnestic data, particularly those regarding alcohol consumption and smoking habits, were annoted in a database. To collect data on alcohol consumption, we considered one drink as containing $12 \mathrm{~g}$ of alcohol (one beer, $330 \mathrm{~mL}, 125 \mathrm{~mL}$, one glass of wine, one shot of whiskey, $40 \mathrm{~mL}$ ), as a reference standard. The individuals recruited were then divided into those who consumed more than two drinks per day and those who did not consume alcohol or who consumed less than two drinks per day. To collect data on smoking habits, we divided the study participants according to the number of cigarettes smoked in $24 \mathrm{~h}$. Individuals who smoked $>20$ cigarettes per day were considered as heavy smokers, individuals who smoked $\leq 20$ cigarettes per day were considered as moderate smokers, and individuals who had never smoked or had stopped smoking for more than 10 years were considered as nonsmokers.

Patients with laryngeal cancer were clinically staged using the AJCC tumor staging system [20]. The study was approved by the ethics committee of the "Magna Græcia" University of Catanzaro.

\section{Sample collection}

All individuals enrolled were asked to rinse their mouths with 2 $\mathrm{mL}$ of saline and to collect the saliva, without dilution, into a sterile container. The sample was immediately stored at $-80^{\circ} \mathrm{C}$. The sampling of saliva was performed on the day before the laryngeal biopsy in the patient group and on the day before surgery in the control group. All individuals enrolled were informed about the purpose and methods of our study and gave their informed consent before being subjected to the collection of saliva.

\section{CD44sol ELISA}

CD44sol levels were detected via sandwich ELISA (eBioscience Human scCDstd Platinum ELISA) using a commercially available ELISA kit (CD44std, soluble, human, Enzo Life Sciences, Inc., Farmingdale, NY), which recognizes all CD44 isoforms. The procedure was performed according to the instruction manual by using fullconcentration samples.

The samples $(20 \mu \mathrm{L})$ were added in duplicate to wells containing $80 \mu \mathrm{L}$ of sample diluent. Then, HRP-conjugated antibody $(50 \mu \mathrm{L})$ was added into individual wells, which were covered with an adhesive film and incubated ( $3 \mathrm{~h}$ at room temperature) on a rotating plate (microplate shaker) at $100 \mathrm{rpm}$. Subsequently, we emptied and washed the wells three times with wash buffer $(400 \mu \mathrm{L})$, followed by the addition of $100 \mu \mathrm{L}$ of tetramethylbenzidine (TMB substrate solution) to each well and incubation at room temperature for about $10 \mathrm{~min}$ without direct exposure to sunlight. We stopped the reaction when color appeared in the wells by adding $100 \mu \mathrm{L}$ of stop solution. The absorbance of the test samples was obtained by spectrophotometric reading at $490 \mathrm{~nm}$. We generated a CD44 duplicate standard curve for notable concentrations to seven points, with a range of values from 0.07 to $4 \mathrm{ng} / \mathrm{mL}$. We calculated the CD44 concentration of our samples according to the relationship between absorbance and concentration of the standard curve.

\section{Statistical analysis}

The MedCalc software (version 12.2.1.0) was used for statistical analysis. The concentration of salivary $\mathrm{CD} 44 \mathrm{sol}$ in relation to clinical anamnestic data was compared between the groups using an independent $t$ test analysis with significance set at $p<0.05$. The correlation between the clinical features of patients with laryngeal cancer (location, histological grade, and $\mathrm{T}$ and $\mathrm{N}$ clinical stage) and the 
Citation: Allegra E, Trapasso S, Sacco A, Aragona T, Belfiore A, et al. (2012) Elisa Detection of Salivary Levels of Cd44sol as a Diagnostic Test for Laryngeal Carcinomas. J Cancer Sci Ther 4: 330-334. doi:10.4172/1948-5956.1000163

salivary concentration of CD44sol was evaluated using an independent $t$ test analysis if the comparison was performed between two groups, or an ANOVA test if the comparison was performed between more than two groups. Significance was set at $p<0.05$. The results were expressed as the mean \pm the standard deviation (SD). The sensitivity and specificity of the tests were calculated for different cut-off points according to the analysis of a receiver operating characteristic (ROC) curve.

\section{Results}

The clinical data and salivary CD44 levels are presented in Table 1. Sixteen out of the $92(17.4 \%)$ patients were affected by laryngeal precancerous lesions (mild dysplasia, $\mathrm{n}=7$; moderate dysplasia, $\mathrm{n}=6$; and severe dysplasia, $n=3$ ) and 76 out of the $92(82.6 \%)$ patients were affected by squamous cell carcinoma of the larynx. The control group consisted of 40 patients with benign disease of the head and neck region (nasal polyps, $\mathrm{n}=10$; chronic rhinosinusitis, $\mathrm{n}=10$; nasal septum deviation, $n=6$; and polyps of the vocal cords, $n=14$ ).

The mean age of the 92 patients recruited was $64 \pm 9$ years; 91 patients were male and one patient was female. The mean age in the control group was $61 \pm 11$ years; 32 individuals were male and eight individuals were female.

The levels of CD44sol were significantly higher in the patient group than they were in the control group $(31.4 \pm 27.3 v$ s. $9 \pm 7.1)$ (Table 1) and were not related to smoking and drinking in the control group. In contrast, higher CD44sol levels were found in nonsmokers and nondrinkers in the patient group.

CD44sol levels were significantly higher in patients affected by carcinoma than they were in patients with precancerous lesions and in the control group $(37.2 \pm 26.7 \mathrm{ng} / \mathrm{mL}, 6.2 \pm 2.8 \mathrm{ng} / \mathrm{mL}$, and $9 \pm 7.1$ $\mathrm{ng} / \mathrm{mL}$, respectively; $p<0.001$ ) (Figure 1). Interestingly, two individuals in the patient group with an initial histopathological diagnosis of moderate/severe dysplasia had high salivary CD44sol levels; subsequently, they were included among the patients with cancer. They exhibited salivary CD44sol levels of $25.7 \mathrm{ng} / \mathrm{mL}$ and $39.4 \mathrm{ng} / \mathrm{mL}$, respectively. $\mathrm{CO}_{2}$ laser cordectomy of the surgical specimen led to the establishment of a histopathological diagnosis of laryngeal carcinoma.

The localization of laryngeal cancer was glottic in 48 out of 76 cases (63.2\%) and supraglottic in 28 out of 76 cases (36.8\%). Clinical TNM staging was T1 in 30 out of the 76 cases (39.5\%), T2 in 28 out of 76 cases

\begin{tabular}{|c|c|c|c|}
\hline Parameters & $\begin{array}{l}\text { Controls } \\
\text { CD44sol ng/mL } \\
\text { No. (\%) mean (SD) }\end{array}$ & $\begin{array}{l}\text { Cases } \\
\text { CD44sol ng/mL } \\
\text { No. (\%) mean (SD) }\end{array}$ & $p$ value \\
\hline \begin{tabular}{|l|} 
Sex \\
Male \\
Female \\
$p$ value
\end{tabular} & $\begin{array}{l}32(80 \%) 8.8(7) \\
8(20 \%) 9.9(8.6) \\
0.79\end{array}$ & $\begin{array}{l}89(96.7 \%) 32.2(27.4) \\
3(3.3 \%) 7.4(4.4) \\
0.1225\end{array}$ & $\begin{array}{l}0.001 \\
0.6693\end{array}$ \\
\hline $\begin{array}{l}\text { Smoking habits } \\
\text { Strong }>20 \text { cig/day } \\
\text { Moderate } \leq 20 \text { cig/day } \\
\text { Never or ex-smokers } \\
>10 \text { (years) } \\
p \text { value }\end{array}$ & $\begin{array}{l}30(75 \%) 10.1(6.3) \\
6(15 \%) 1.5(0.3) \\
4(10 \%) 12.1(14) \\
0.125\end{array}$ & $\begin{array}{l}64(69.5 \%) 35.2(28) \\
18(19.5 \%) 14.5(11.8) \\
10(11 \%) 37.1(33) \\
0.013\end{array}$ & $\begin{array}{l}0.001 \\
0.0773 \\
0.3314\end{array}$ \\
\hline $\begin{array}{l}\text { Drinking habits } \\
>2 \text { drinks/day } \\
\text { No or } \leq 2 \text { drinks/day } \\
p \text { value }\end{array}$ & $\begin{array}{l}18(45 \%) 9.3(7.3) \\
22(55 \%) 8.8(7.2) \\
0.8797\end{array}$ & $\begin{array}{l}46(50 \%) 25.6(14.8) \\
46(50 \%) 37.2(35) \\
0.0413\end{array}$ & $\begin{array}{l}0.0023 \\
0.0102\end{array}$ \\
\hline Total & 409 (7.1) & $9231.4(27.3)$ & 0.0004 \\
\hline
\end{tabular}

Table 1: Demographic data, risk factors, and CD44sol data for cases and controls.

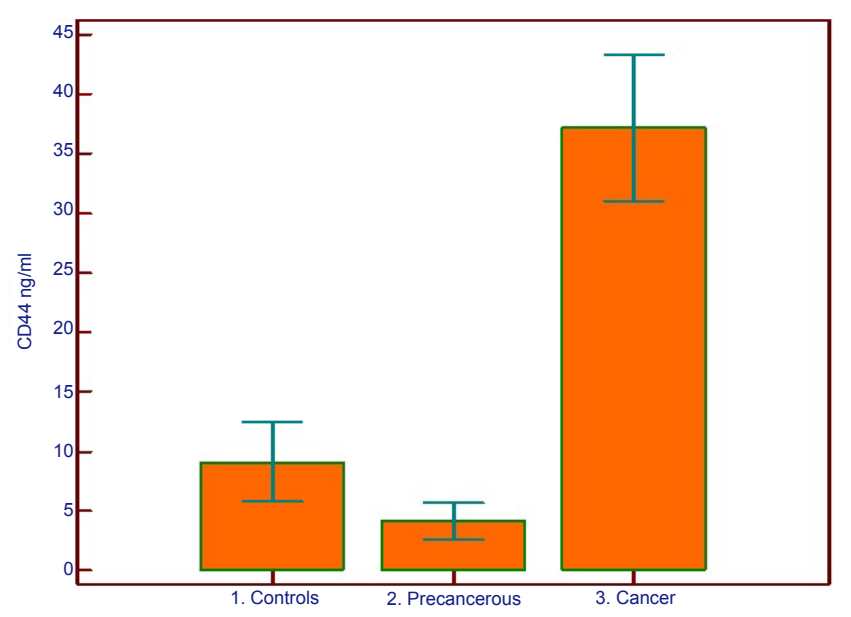

Figure 1: Mean CD44sol levels of the groups of individuals enrolled: control, dysplasia, and cancer groups.

\begin{tabular}{|l|l|l|l|}
\hline Parameters & No. (\%) & $\begin{array}{l}\text { CD44sol ng/mL } \\
\text { mean (SD) }\end{array}$ & p value \\
\hline $\begin{array}{l}\text { Site } \\
\text { Glottic }\end{array}$ & $28(36.8 \%)$ & $35.6(30)$ & 0.703 \\
\hline Histological grade & $48(63.2 \%)$ & $38(24.9)$ & \\
Well differentiated & $10(13.1 \%)$ & $42.5(29)$ & 0.763 \\
Moderately differentiated & $46(60.5 \%)$ & $37(22.7)$ & \\
Poorly differentiated & $20(26.4 \%)$ & $34.8(34)$ & \\
\hline Tumor size & $30(39.5 \%)$ & $32.3(23.3)$ & \\
\hline T1 & $28(36.8 \%)$ & $39.7(29)$ & 0.461 \\
\hline T2 & $14(18.4 \%)$ & $44.6(30)$ & \\
\hline $\begin{array}{l}\text { T3 } \\
\text { T4 }\end{array}$ & $4(5.3 \%)$ & $29.9(22.4)$ & \\
\hline $\begin{array}{l}\text { Lymph node status } \\
\text { pN0 } \\
\text { pN }\end{array}$ & $54(71 \%)$ & $35.6(24.5)$ & 0.446 \\
\hline $\begin{array}{l}\text { Clinical stage } \\
\text { Early clinical stage (I-II) }\end{array}$ & $22(29 \%)$ & $40.8(31.9)$ & \\
\hline \begin{tabular}{l} 
Advanced clinical stage (III-IV) \\
\hline
\end{tabular} & $42(55.3 \%)$ & $32.3(20.5)$ & 0.09 \\
\hline
\end{tabular}

Table 2: Mean levels of salivary CD44sol according to tumor features.

(36.8\%), T3 in 14 out of 76 cases (18.4\%), and T4 in 4 out of 76 (5.3\%) cases. Among the 76 patients, $54(71 \%)$ had $\mathrm{N}_{0}$ clinical stage and 22 (29\%) had $\mathrm{N}_{+}$clinical stage.

The analysis of the clinical data in relation to the concentrations of salivary CD44sol revealed an absence of significant differences between the study groups according to tumor site, histological grade, and clinical stage of $\mathrm{T}$ and $\mathrm{N}$ (Table 2).

CD44sol salivary levels were higher in advanced-stage disease (stages III and IV) than they were in early-stage disease (43.2 \pm 32.2 vs. $32.2 \pm 20.5 \mathrm{ng} / \mathrm{mL})$. However, this difference did not appear to be significant $(p=0.09)$ (Figure 2).

Sensitivity and specificity values derived from various predicted probability cut-off points based on the ROC curve are summarized in Figure 3. Best accuracy was obtained using a predictive probability cut-off point of $10 \mathrm{ng} / \mathrm{mL}$, with corresponding estimates of sensitivity and specificity of $89.5 \%$ and $83.3 \%$, respectively, with six false-positive and eight false-negative values. At cut-off points greater than $17.4 \mathrm{ng} /$ $\mathrm{mL}$, the sensitivity and specificity of the test were $76.3 \%$ and $91.6 \%$, 


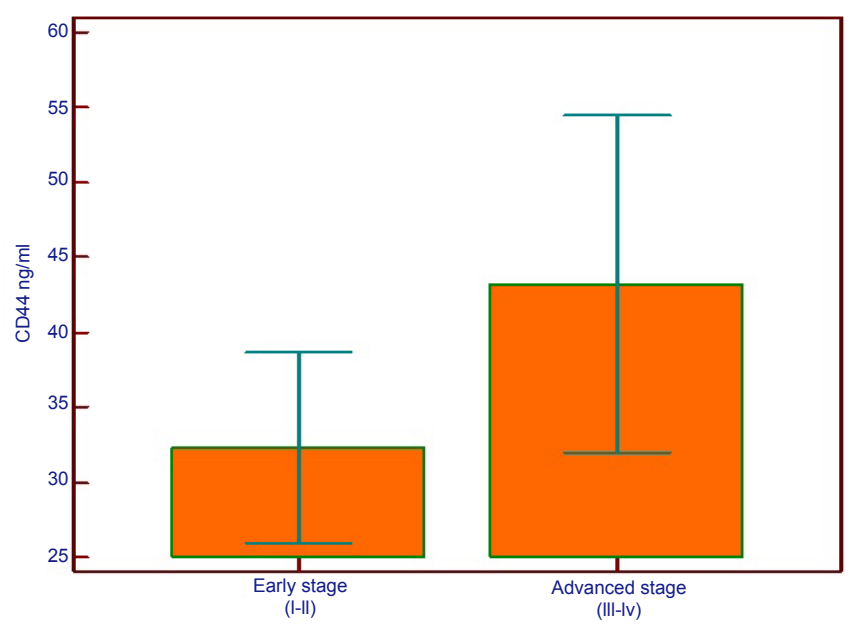

Figure 2: CD44sol levels in the group of tumors according to clinical stage (early and advanced).

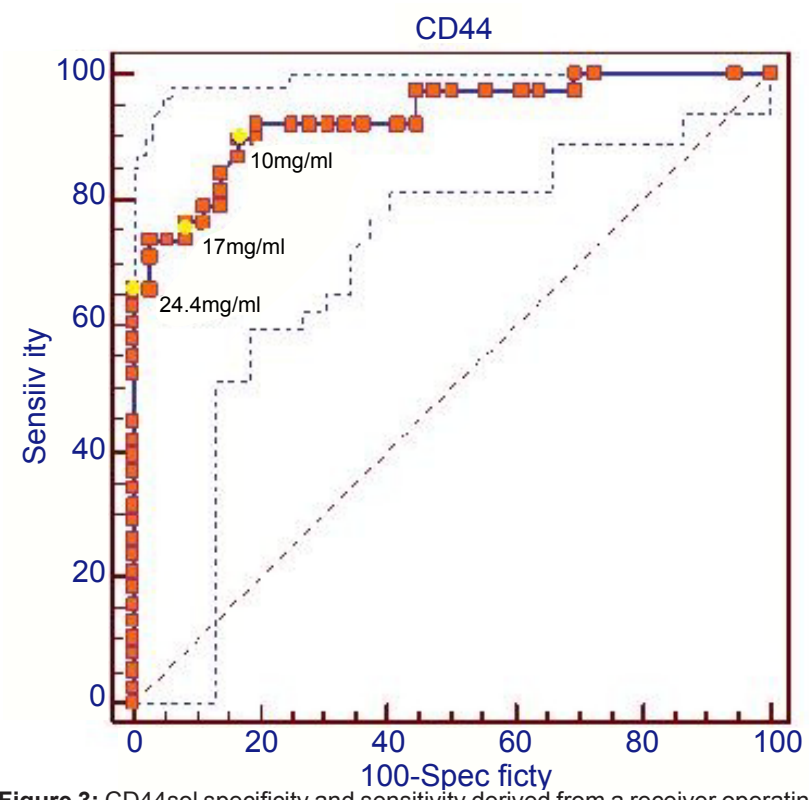

Figure 3: CD44sol specificity and sensitivity derived from a receiver operating characteristic (ROC) curve at different cut-off points.

respectively, with three false-positive and 18 false-negative values. At cut-off points greater than $24.4 \mathrm{ng} / \mathrm{mL}$, the sensitivity and specificity of the test were $65.7 \%$ and $100 \%$ respectively.

\section{Discussion}

Studies on the use of enzyme immunoassays for the detection of CD44sol in saliva for diagnostic purposes in head and neck cancers are scarce [10-22]. Unlike other reports, our study was limited to laryngeal sites exclusively, which was intended to determine the specificity of the test according to the laryngeal site and to limit the possible discrepancies caused by the well-known biological diversity of the head and neck tumors, as reflected by the variation of clinical behavior according to location.

Data are conflicting regarding the expression of CD44 in head and neck tumors in relation to their subsite. In carcinomas of the oral cavity and oropharynx, the evidence available suggests that low expression of CD44 correlates with increased metastasizing capacity and poor prognosis [23-26]. Conversely, in laryngeal carcinomas, the high expression of CD44 appears to correlate with poor prognosis because of metastasis (regional or distant) and radiotherapy resistance [27-29].

In our study, the levels of CD44sol detected in the saliva of patients with laryngeal cancer were significantly higher than they were in patients with precancerous lesions and in the control group.

We must emphasize the relevance of the results obtained for two patients with an initial histopathological diagnosis of dysplasia, who had high levels of CD44sol and whose final diagnosis of the surgical specimen was cancer. These data seem to correlate with the role of the CD44 antigen as a marker of CSCs in laryngeal tumors.

According to the hierarchical theory [30] of tumor development, CSCs represent a cell population that fuels tumor growth, confers radio- and chemotherapy resistance, and promotes local and distant metastasis. The remaining cellular components of the tumor mass would consist of aberrant differentiated cells that have lost the ability to replicate [17].

The finding of high CD44sol levels in the saliva of patients affected by cancer might be related to the amount of the extracellular fraction of the CD44 antigen released by stem cells that remain on the tumor mass. Despite we did not find correlations between CD44sol levels and the independent factors grade and $\mathrm{T}$ and $\mathrm{N}$ stage; however, we found that high CD44sol levels correlated with advanced disease, probably because of the increased presence of CSCs in advanced stages of disease. We are currently conducting a study to test this hypothesis.

In their study, Franzmann et al. [10,21,22] considered various subsites of the head and neck region and reported lower average levels of CD44 compared with those encountered here in the group of patients with laryngeal carcinoma. However, this difference might be due to methodological differences in the collection of the sample (i.e., oral rinse $v s$. whole saliva).

Based on our results, the diagnostic power of CD44sol determination in the saliva of patients with laryngeal carcinoma seems promising and not influenced by risk factors. The CD44sol levels determined in the control group were not significantly different regarding smoking and drinking, which is in agreement with the results of Franzmann et al. $[10,21,22]$. This finding was confirmed in the patient group, in which we found surprisingly high levels of CD44sol in nonsmokers and nondrinkers, despite the observation that the majority of the patients were smokers and half of them were drinkers, reflecting the incidence of smoking and alcohol use in the Italian population.

The observed sensitivity of ELISA ranged from $65.7 \%$ to $89.5 \%$ and its specificity ranged from $83.3 \%$ to $100 \%$, depending on the cutoff value selected. These data are superior to those obtained in other studies using various markers and different methods of investigation, such as loss of heterozygosity [31], methylation-specific markers [32], telomerase activity [33], mitochondrial DNA mutations [34] and, recently, multiplexed immunobead-based technology [35]. Those investigations reached a sensitivity that ranged from 35 to $84.5 \%$ and a specificity that ranged from 30 to $98 \%$ and required long run times, skilled personnel, and expensive technology. Moreover, the technology and skilled personnel are not widely available; thus, they represent inadequate conditions for an ideal screening method.

The determination of CD44sol levels in the saliva of patients with 
Citation: Allegra E, Trapasso S, Sacco A, Aragona T, Belfiore A, et al. (2012) Elisa Detection of Salivary Levels of Cd44sol as a Diagnostic Test for Laryngeal Carcinomas. J Cancer Sci Ther 4: 330-334. doi:10.4172/1948-5956.1000163

laryngeal carcinoma using ELISA, compared with other screening tests (such as PSA for prostate cancer [36] and the Pap test for cervical cancer [37] seems to be a promising diagnostic test in terms of high sensitivity and specificity, low cost and noninvasiveness of the technique.

\section{Conclusion}

The determination of CD44sol levels as a potential diagnostic marker of laryngeal cancer in the saliva of patients with laryngeal carcinoma using ELISA seems to be a promising method. However, additional and larger studies are needed to confirm these results.

\section{Competing Interests}

The authors declare that they have no competing interests. Non-financial competing interest.

\section{References}

1. Ferlay J, Parkin DM, Steliarova-Foucher E (2010) Estimates of cancer incidence and mortality in Europe in 2008. Eur J Cancer 46: 765-781.

2. Liu J, Duan $Y$ (2012) Saliva: A potential media for disease diagnostics and monitoring. Oral Oncol 48: 569-577.

3. Naor D, Nedvetzki S, Golan I, Melnik L, Faitelson Y (2002) CD44 in cancer. Crit Rev Clin Lab Sci 39: 527-579.

4. Huet S, Groux H, Caillou B, Valentin H, Prieur AM, et al. (1989) CD44 contributes to T cell activation. J Immunol 143: 798-801.

5. Toyama-Sorimachi N, Miyasaka M (1994) A sulfated proteoglycan as a novel ligand for CD44. J Dermatol 21: 795-801.

6. Peterson RM, Yu Q, Stamenkovic I, Toole BP (2000) Perturbation of hyaluronan interactions by soluble CD44 inhibits growth of murine mammary carcinoma cells in ascites. Am J Pathol 156: 2159-2167.

7. Mayer S, Zur Hausen A, Watermann DO, Stamm S, Jäger M, et al. (2008) Increased soluble CD44 concentrations are associated with larger tumor size and lymph node metastasis in breast cancer patients. J Cancer Res Clin Oncol 134: 1229-1235.

8. Masson D, Denis MG, Denis M, Blanchard D, Loirat MJ, et al. (1999) Soluble CD44: quantification and molecular repartition in plasma of patients with colorectal cancer. Br J Cancer 80: 1995-2000.

9. Van Hal NL, Van Dongen GA, Ten Brink CB, Heider KH, Rech-Weichselbraun I, et al. (1999) Evaluation of soluble CD44v6 as a potential serum marker for head and neck squamous cell carcinoma. Clin Cancer Res 5: 3534-3541.

10. Franzmann EJ, Reategui EP, Carraway KL, Hamilton KL, Weed DT, et al. (2005) Salivary soluble CD44: a potential molecular marker for head and neck cancer. Cancer Epidemiol Biomarkers Prev 14: 735-739.

11. Koukourakis MI, Giatromanolaki A, Tsakmaki V, Danielidis V, Sivridis E (2012) Cancer stem cell phenotype relates to radio-chemotherapy outcome in locally advanced squamous cell head-neck cancer. Br J Cancer 106: 846-853.

12. Bonnet D, Dick JE (1997) Human acute myeloid leukemia is organized as a hierarchy that originates from a primitive hematopoietic cell. Nat Med 3: 730777 .

13. Al-Hajj M, Wicha MS, Benito-Hernandez A, Morrison SJ, Clarke MF (2003) Prospective identification of tumorigenic breast cancer cells. Proc Natl Acad Sci U S A 100: 3983-3988.

14. Singh SK, Clarke ID, Terasaki M, Bonn VE, Hawkins C, et al. (2003) Identification of a cancer stem cell in human brain tumors. Cancer Res 63: 5821-5828.

15. Collins AT, Berry PA, Hyde C, Stower MJ, Maitland NJ, et al. (2005) Prospective identification of tumorigenic prostate cancer stem cells. Cancer Res 65: 1094610951.

16. Dalerba P, Dylla SJ, Park IK, Liu R, Wang X, et al. (2007) Phenotypic characterization of human colorectal cancer stem cells. Proc Natl Acad Sci U S A 104: 10158-10163.

17. Li C, Heidt DG, Dalerba P, Burant CF, Zhang L, et al. (2007) Identification of pancreatic cancer stem cells. Cancer Res 67: 1030-1037.

18. Ho MM, Ng AV, Lam S, Hung JY (2007) Side population in human lung cancer cell lines and tumors is enriched with stem-like cancer cells. Cancer Res 67: 4827-4833.

19. Prince ME, Sivanandan R, Kaczorowski A, Wolf GT, Kaplan MJ, et al. (2007) Identification of a subpopulation of cells with cancer stem cell properties in head and neck squamous cell carcinoma. Proc Natl Acad Sci U S A 104: 973-978.

20. Brandwein-Gensler M, Smith RV (2010) Prognostic indicators in head and neck oncology including the new 7 th edition of the AJCC staging system. Head Neck Pathol 4: 53-61.

21. Franzmann EJ, Reategui EP, Pedroso F, Pernas FG, Karakullukcu BM (2007) Soluble CD44 is a potential marker for the early detection of head and neck cancer. Cancer Epidemiol Biomarkers Prev 16: 1348-1355.

22. Franzmann EJ, Reategui EP, Pereira LH, Pedroso F, Joseph D, et al. (2012) Salivary protein and solCD44 levels as a potential screening tool for early detection of head and neck squamous cell carcinoma. Head Neck 34: 687-695.

23. Wang SJ, Wong G, de Heer AM, Xia W, Bourguignon LY (2009) CD44 variant isoforms in head and neck squamous cell carcinoma progression. Laryngoscope 119: 1518-1530.

24. Rajarajan A, Stokes A, Bloor BK, Ceder R, Desai H, et al. (2012) CD44 expression in oro-pharyngeal carcinoma tissues and cell lines. PLoS One 7: e28776.

25. Lindquist D, Ahrlund-Richter A, Tarján M, Tot T, Dalianis T, et al. (2012) Intense CD44 expression is a negative prognostic factor in tonsillar and base of tongue cancer. Anticancer Res 32: 153-161.

26. Kokko LL, Hurme S, Maula SM, Alanen K, Grénman R, et al. (2011) Significance of site-specific prognosis of cancer stem cell marker CD44 in head and neck squamous-cell carcinoma. Oral Oncol 47: 510-516.

27. Yüce I, Bayram A, Cağlı S, Canöz O, Bayram S, et al. (2011) The role of CD44 and matrix metalloproteinase-9 expression in predicting neck metastasis of supraglottic laryngeal carcinoma. Am J Otolaryngol 32: 141-146.

28. Uwa N, Kataoka TR, Torii I, Sato A, Nishigami T, et al. (2011) CD44 expression is related to poor prognosis of hypopharyngeal squamous cell carcinoma. Acta Otolaryngol 131: 323-329.

29. de Jong MC, Pramana J, van der Wal JE, Lacko M, Peutz-Kootstra CJ, et al (2010) CD44 expression predicts local recurrence after radiotherapy in larynx cancer. Clin Cancer Res 16: 5329-5338.

30. Reya T, Morrison SJ, Clarke MF, Weissman IL (2001) Stem cells, cancer, and cancer stem cells. Nature 414: 105-111.

31. Spafford MF, Koch WM, Reed AL, Califano JA, Xu LH, et al. (2001) Detection of head and neck squamous cell carcinoma among exfoliated oral mucosal cells by microsatellite analysis. Clin Cancer Res 7: 607-612.

32. Carvalho AL, Jeronimo C, Kim MM, Henrique R, Zhang Z, et al. (2008) Evaluation of promoter hypermethylation detection in body fluids as a screening/diagnosis tool for head and neck squamous cell carcinoma. Clin Cancer Res 14: 97-107.

33. Califano J, Ahrendt SA, Meininger G, Westra WH, Koch WM, et al. (1996) Detection of telomerase activity in oral rinses from head and neck squamous cell carcinoma patients. Cancer Res 56: 5720-5722.

34. Allegra E, Garozzo A, Lombardo N, De Clemente M, Carey TE (2006) Mutations and polymorphisms in mitochondrial DNA in head and neck cancer cell lines. Acta Otorinolaryngol Ital 26: 185-190.

35. Linkov F, Lisovich A, Yurkovetsky Z, Marrangoni A, Velikokhatnaya L, et al (2007) Early detection of head and neck cancer: development of a nove screening tool using multiplexed immunobead-based biomarker profiling Cancer Epidemiol Biomarkers Prev 16: 102-107.

36. Hoffman RM (2012) ACP Journal Club. Periodic PSA-based screening in men 55 to 69 years of age reduced prostate cancermortality. Ann Intern Med 157: JC2-JC4.

37. Chen H, Shu HM, Chang ZL, Wang ZF, Yao HH, et al. (2012) Efficacy of Pap Test in Combination with ThinPrep Cytological Test in Screening for Cervical Cancer. Asian Pac J Cancer Prev 13: 1651-1655. 